\title{
TOLEDO EN EPOCA DE LA FRONTERA
}

Miguel Angel Ladero Quesada

Universidad Complutense. Madrid

\section{I.-INTRODUCCION. LOS ANTECEDENTES}

Toledo fue ocupada, después de siete años de guerra en su territorio, por capitulación, y pasó a manos del rey de Castilla y León, Alfonso $\mathrm{VI}$, en 1085. El relato que sigue se sitúa en plena época de las Cruzadas, siglos XII y XIII, pero justamente en el otro extremo del Mediterráneo e, indudablemente, con unas consecuencias mucho más duraderas para la historia europea. Sin embargo, a finales del siglo XI tenía ya Toledo una larga historia a sus espaldas y, precisamente por eso, su conquista por los hispanocristianos tuvo tanta importancia y fama.

La ciudad había sido capital política y eclesiástica del reino hispanovisigodo, hasta su destrucción por los musulmanes a comienzos del siglo VIII, y conservaba un valor de símbolo en el proceso de reconquista o restauración frente al Islam en el que se sentían inmersos los españoles del siglo XI. Pero tiene más valor ahora, para nuestro objeto presente, considerar algunas peculiaridades del Toledo islámico que, en parte, continuaron vivas después de la conquista cristiana.

En la ciudad de Toledo, aunque la islamización fue profunda, la mayoría de la población continuó siendo hispana, de muladies, y hubo una importante comunidad cristiana, de mozárabes, arabizados en su lengua y costumbres, pero que conservaban la fe de sus antepasados. Ambos grupos se sentían solidarios, en los siglos VIII y IX, frente a los

«Texto de la conferencia publicada en Alicante en mayo de 1983 con motivo del ciclo que sobre La socieded peninsular en la Edad Media organizaron el Departamento de Historia Medieval de la Universidad de Alicante y la Caja de Ahorros Provincial. 
nutridos grupos beréberes instalados en zonas rurales próximas y en fortalezas (Guadalajara, Medinaceli, Talavera, Medellín), y a los escasos árabes que llegaron a la zona (vg., los asentados en Calatrava). En la ciudad y su entorno hubo, pues, pocos inmigrantes, el sentimiento de autonomia frente a Córdoba, continuo en el siglo IX, fue obra de la población indígena, y se plasmó en diversas revueltas y estados de secesión en 807,829 a 837 y 852 a 932 . Toledo se sabía fuerte, además, porque era cabecera y centro organizativo de toda la marca o frontera media contra los cristianos del $\mathrm{N}$, en la retaguardia del Sistema Central, con más de 400 kilómetros de extensión, y también etapa obligada en las comunicaciones entre Córdoba y la frontera superior (Zaragoza), a través del corredor natural formado por los ríos Jalón y Jiloca, y entre Córdoba, también, y la costa levantina. La pérdida de Toledo hubiera provocado la ruptura en dos de Al-Andalus, y así sucedió, efectivamente, en 1085.

La plena individualización política de Toledo y su región se produjo al disgregarse el Califato de Córdoba, a partir del año 1008. Se formó entonces un extenso taifa o reino musulmán regional, con capital en la ciudad, extendido sobre unos $85.000 \mathrm{Km}^{2}$, que comprendía las tierras de la Meseta Sur, desde los macizos de la Ibérica, al $\mathrm{E}$, hasta bien entrada la actual Extremadura al $\mathrm{O}$, desde el Sistema Central, al $\mathrm{N}$, hasta Sierra Morena, al S. Por vez primera se perfiló, desde el punto de vista histórico-político, el área de lo que sería, en el futuro, Castilla la Nueva, o reino de Toledo, con sus relaciones y tendencias hegemónicas sobre el Levante, por un lado (estrecha relación con Valencia), Córdoba, por otro (el camino Toledo-Córdoba era un eje militar y mercantil de gran importancia), y, en tercer lugar, las tierras occidentales del reino taifa de Mérida.

II.-UN SIGLO Y MEDIO DE CONQUISTA, FRONTERA Y REPOBLACION. 1085-1236/38

Durante 150 años, desde su propia conquista en 1085 hasta la caída de las plazas extremeñas (Trujillo, Cáceres, Mérida, Badajoz), de la Andalucía alta y media (Úbeda, Baeza, Córdoba) y de Levante (Valencia), entre 1224 y 1238, fue Toledo cabecera de una amplísima zona fronteriza, la segunda de las grandes fronteras medievales hispánicas, por orden cronológico (la primera había sido la del Duero en los siglos IX y X), en la que se enfrentaron repetidamente y con dureza los cristianos y los musulmanes, sobre todo en los períodos de dominio y organi- 
zación militar a cargo de los norteafricanos almorávides (1086-1118) y almohades (1157-1212). Las circunstancias de las conquistas, repoblaciones y asentamientos cristianos dependen estrechamente de las peripecias militares, que no puedo detenerme a enumerar ahora. Veamos, tan sólo, un esquema general, ilustrado con el mapa adjunto.

Entre 1085 y 1118 , fecha de la conquista de Zaragoza por los cristianos, y del comienzo de la decadencia militar de los almoravides, Toledo sufrió tres asedios, el rey castellano-leonés fue derrotado por los almorávides en dos batallas campales y, en definitiva, sólo se pudo asegurar la defensa y repoblación de las principales plazas fortificadas, sus entornos y los corredores que las unían, todo ello al $\mathrm{N}$. del río Tajo, desde Medinaceli, Atienza, Hita, Guadalajara (línea del Henares), desde Buitrago, Uceda, Madrid (línea del Jarama), aunque Alcalá de Henares no fue recuperada hasta 1127, a la propia Toledo y las plazas de la línea del Alberche (Alamín, Maqueda, Talavera).

De 1118 a 1157, aprovechando la presión militar mucho más baja que ejercía el Islam, se repueblan las tierras vacías entre los islotes citados y, además, el dominio de Zorita y Huete, y el de Oreja, Ocaña y Mora, permiten establecer vanguardias muy sólidas al otro lado del Tajo, de modo que Toledo deja de estar en primera línea de la frontera desde 1136-38.

Esta situación se consolida entre 1157 y 1224, tanto en el sector central o toledano como, sobre todo, en el oriental (Uclés, tomada en 1157, alto Júcar, zona de Cuenca, tomada en 1177, y de Alarcón, 1183), aprovechando que en este último el dominio almohade no se estableció y fueron tierras en poder del "Rey Lobo", un hispano-musulmán más propicio a los pactos con cristianos, hasta su muerte en 1172. Entre la gran derrota castellana de Alarcos (1195) y la victoria de Las Navas de Tolosa (1212), el proceso repoblador casi se detuvo, pero en 1215 se reanudó en torno a la posición adelantada de Alcaraz.

Desde 1224 a 1276 se completa la repoblación de Castilla la Nueva, ya sin el peligro de la frontera, puesto que se ha conquistado Andalucía y las plazas extremeñas y levantinas en poder de los musulmanes. Hay que mencionar, también, las repoblaciones tardías, a veces hasta el siglo XV, en zonas de retaguardia, muy al $N$, en los valles del Tiétar $y$ del Guadarrama.

Se comprende bien, por tanto, que Toledo haya sido un lugar de encuentro entre dos grandes civilizaciones, hostiles pero próximas, du- 


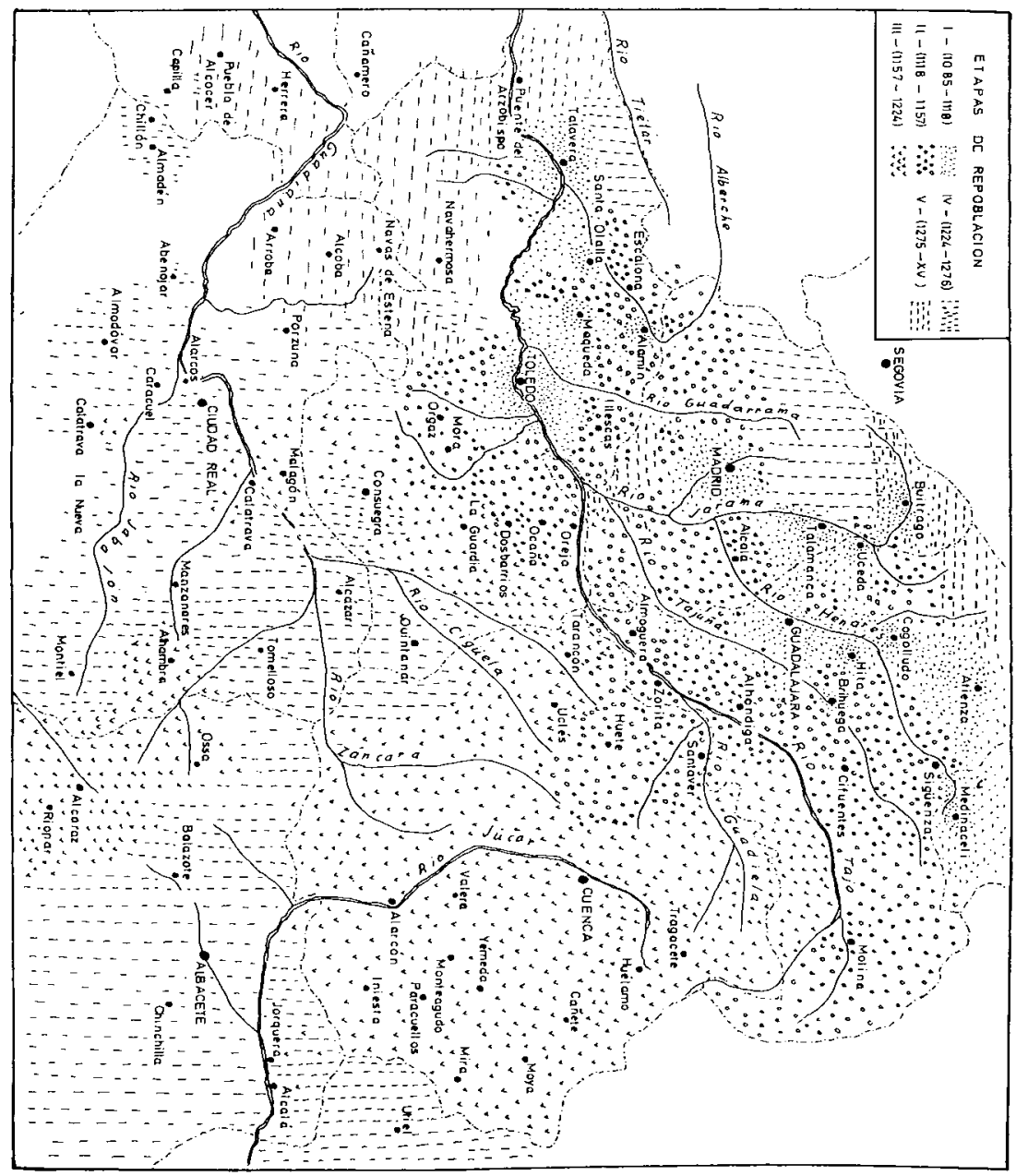

Repoblación de Castilla La Nueva (J. González) 
rante siglo y medio. Continuaba con ello una tradición anterior, en su época de ciudad islámica, y preludiaba, también, la continuación aminorada de la ósmosis cultural cristiano-islamo-judaica en los siglos XIII y XIV, dentro de su condición dominante de ciudad castellana.

De todas las áreas de Castilla la Nueva conquistadas en los ss. XII y XIII centrará nuestro interés la de Toledo, ciudad, con su término rural próximo, hasta unos 30 o 40 kilómetros de radio, más algunas prolongaciones, situadas casi siempre en el área más poblada de la cuenca media del Tajo, en el triángulo comprendido entre Guadalajara, la propia Toledo y Talavera. Ya era la zona mejor organizada y poblada, y la más apta para la repoblación, cuando ocurrió la conquista de Alfonso $\mathrm{VI}$ a finales del siglo XI, se consolidó como tal en los siglos XII y XIII, y persistía aquella primacía demográfica y de poblamiento tanto a fines del siglo XVI, cuando se redacta la gran encuesta catastral conocida como "Relaciones Topográficas", como en la actualidad, en relación con otras tierras de Castilla la Nueva.

Primacía que existe también, en otro orden de cosas, con relación a los estudios históricos, debido al atractivo que ejerce Toledo sobre investigadores de la historia, la literatura y el arte, y a la riqueza relativamente mayor de sus archivos, muy en especial el de la catedral. Por eso, aunque no deseo insistir mucho en este aspecto, me ha parecido importante facilitar al final algunas indicaciones bibliográficas que son, al mismo tiempo, el fundamento principal de esta conferencia.

\section{III.-POBLAMIENTO, POBLACION, GRUPOS RELIGIOSOS Y SOCIALES}

Los conquistadores y repobladores que acudieron a partir de 1085 encontraron no sólo población ya instalada, sino también suficientes emplazamientos en uso para el poblamiento urbano y rural, paisajes agrarios y tipos de cultivo en pleno vigor. No era, como ocurría con las extremaduras entre Duero y Sistema Central, una tierra arrasada y desertizada, donde todo tenía que partir de la iniciativa colonizadora. Por el contrario, las peculiaridades y permanencias de la época islámica hubieron de ser tenidas en cuenta y se integraron en el nuevo sistema social, de poblamiento y relación hombre/medio, de diversa manera.

Las formas de poblamiento y los emplazamientos no se modificaron. Toledo siguió siendo la ciudad principal, en su magnífico sitio de acrópolis sobre un peñón cercado por el Tajo en sus tres cuartas partes, con el plano y las características propias de una urbe islámica occidental. Componían su séquito un conjunto de "villas" de menor importan- 
cia, todas preexistentes, pero en las que se hicieron labores de fortificación y edificación notables en los siglos XII y XIII: Talavera, Madrid, Alcalá, Guadalajara. El poblamiento rural, en el entorno de Toledo, estaba formado por decenas de aldeas, llamadas alquerias, y más adelante lugares, que persistieron en su inmensa mayoria, hasta la crisis de los siglos XIV y XV.

Hasta entonces, también, hubo gran continuidad en los paisajes agrarios y tipos de cultivo del campo toledano, más intensamente explotado que otras áreas de Castilla la Nueva, según tradiciones islámicas y mozárabes. La riqueza agrícola del territorio había sido ensalzada, tal vez con exceso, por autores árabes (Idrisí, Rasis), y se reflejó en algunos tratados de agronomía escritos por los toledanos Ibn Bassal e Ibn Wafid, en el siglo XI. Destacaban, tanto en el término de Toledo como también en el de Talavera, las vegas del Tajo y sus afluentes, que permitían la irrigación: viñas, huertos, frutales. Poco antes de la conquista habría trazado el agrónomo Ibn Wafid la famosa «Huerta del Rey", junto a Toledo. Ni que decir tiene que el uso del agua para riego, como fuerza motriz, y de las pesquerías, estaba muy regulado. Contaban también las terrazas de secano, destinadas al trigo y otros cereales, en rotación bienal. Era ya zona apta para el olivar y aprovechada para la plantación de frutales, árboles madereros (pino), aparte de la madera que bajaba de las serranías ibéricas por el Tajo y morera para la cría de gusano de seda. Los conocimientos agronómicos impulsaron el empleo de abonos animales -eran muy numerosos los gallineros y los palomares-; sin embargo, el desarrollo de la ganadería en la zona toledana era relativamente escaso; apenas se practicaba todavía la trashumancia de ganado ovino, aunque se criaba ganado bovino suficiente para la labor del campo, y equino para la guerra, sobre todo en las tierras sureñas del alfoz toledano. Hay que mencionar, también, la importancia que tuvieron siempre, en los Montes de Toledo, las colmenas, siendo, como era, grande el consumo de miel, y determinados productos de caza, en especial las pieles de conejo, cazados con trampas o losas.

A partir de esta situación actuaron los organizadores de la repoblación, desde el momento de la conquista cristiana, y los nuevos pobladores, como ya he indicado, la tuvieron en cuenta. Al permanecer la mayor parte de la tierra bajo jurisdicción regia (realengo), los monarcas son los máximos organizadores de la repoblación y, como agentes suyos, los municipios, que fijan los términos o alfoces, reparten tierra entre pobladores, a quiñón, en lotes o heredamientos relativamente iguales, y ordenan la explotación de las tierras de uso común. La Iglesia fue gran propulsora de la repoblación en las villas y aldeas cuya juris- 
dicción la donaron los reyes, como fueron Alcalá de Henares y Brihuega, que pasaron a manos de los arzobispos de Toledo. Algunos conventos urbanos de Toledo, la sede arzobispal, y el cabildo catedralicio contribuyeron a modificar, como veremos, la estructura de la propiedad agraria, mediante compras de tierras y recepción de donaciones, además de haber recibido grandes predios o donadios en los repartimientos, y aldeas (15 la sede episcopal entre 1086 y 1115, según Julio González). Pero apenas hubo colonización agraria de tipo monástico, al contrario de lo que había ocurrido en las tierras del NO y de la cuenca del Duero, ni tampoco, en las tierras toledanas que ahora consideramos, la de Ordenes Militares, tan decisiva en otras áreas de Castilla la Nueva. Respecto a las cesiones de jurisdicción a nobles laicos sobre diversos territorios, para que organizasen su repoblación, fueron escasas: algo más abundantes entre 1166 y 1192, que fue el período mejor de la tarea pobladora en áreas rurales y bajo la forma de prestimonio, típica del derecho hispánico, pero no tuvieron mucha importancia, ni anticipan el gran proceso señorializador de los siglos XIV y XV.

Desde luego, la buena población de la ciudad de Toledo fue objeto de especial cuidado, desde los primeros momentos, pero ni siquiera en este caso mejor conocido se puede responder a la pregunta sobre cuántos eran los habitantes, tanto los de antigua residencia que permanecieron -mozárabes, musulmanes, judíos- como los nuevos pobladores castellanos, francos y de otras partes. Se sabe que el Toledo islámico pudo albergar, en los mejores momentos, 37.000 habitantes, pero seguramente eran muchos menos en 1085. Sin embargo, a lo largo de los ss. XII y XIII, la ciudad sería la mayor aglomeración de la España cristiana, aunque no superase los $25.000 \mathrm{~h}$.

Pasemos, en consecuencia, al análisis cualitativo de los grupos de población toledanos. Primero, las minorías étnico-religiosas de musulmanes mudéjares y judios, que por su propia condición permanecian en muchos aspectos en los márgenes del nuevo sistema social. Segundo, los grupos cristianos, según su origen: mozárabes indígenas, repobladores castellanos y francos. La identidad de fe y los intereses comunes permitieron, en este caso, la aparición de criterios globales de jerarquización y organización social, aunque permaneciesen, más o menos tiempo, los específicos de cada grupo.

Los musulmanes. Las referencias documentales sobre los musulmanes, después de la conquista, son escasas, a pesar de su presencia predominante y numerosa antes de que ocurriera. Muchos emigraron antes de la conquista o a raíz de ella, sobre todo los cuadros intelectuales y administrativos, todos aquellos que tuvieron medios para atender 
la exigencia islámica, según la cual el fiel debe vivir en país de Islam. Otros se convirtieron, según testimonios de época, y sobre todo de los años 1118 a 1137, durante la decadencia almorávide, aunque el silencio impide saber cuántos y cómo. De todas maneras, permaneció en Toledo y su término una comunidad musulmana mudéjar, la primera de importancia que conoció la España cristiana, respetada en su libertad personal, en su residencia y oficio, en la propiedad privada de sus bienes, según estipulaba la capitulación de la ciudad. He aquí un fenómeno nuevo y trascendental durante varios siglos en la historia hispánica, los fundamentos del mudejarismo en territorio castellano-leonés, recogiendo una práctica de coexistencia que tenía su origen en el tradicional respeto del Islam hacia la "gente del libro" (cristianos y judíos), sólo que ahora los términos se habían invertido.

Los mudéjares serían, en general, gente modesta, dedicada a oficios artesanos, al pequeño comercio, o al cultivo de la tierra como aparceros. Vivirían en Toledo entremezclados con el resto de la población y bien diferenciados de los moros cautivos venidos de otras partes por causa de la guerra. No es posible sostener que fuesen muy numerosos, porque el silencio de los documentos es grande y, sobre todo, porque en los siglos siguientes su número es muy escaso, pero se puede suponer que los grupos mudéjares que aparecen en Segovia, Ávila, Valladolid, Burgos y otras ciudades de la cuenca del Duero desde finales del siglo XII son de procedencia toledana, y acudirian a ellas en busca de lugares más alejados de la frontera, donde su presencia no despertara sospechas de colaboración política con el mundo islámico.

Los judios, al igual que los mudéjares, vivieron en Toledo gracias a la protección personal que les dispensaba el rey, su señor, como grupo específico, ajeno a la sociedad hispanocristiana. Conservaron el barrio que ya tenian en época islámica, entre las collaciones de Santo Tomé y San Román y el Tajo, pero su número se incrementó mucho durante el siglo XII, en especial en la segunda mitad, con los que huian del valle del Guadalquivir, debido a la intolerancia de los almohades. Las condiciones eran entonces mucho mejores en el Toledo cristiano, a pesar de momentos de agresión, como los ocurridos en 1109, cuando murió Alfonso $\mathrm{VI}$; o en 1212, al paso de los cruzados ultrapirenaicos que acudían a la campaña de Las Navas de Tolosa. De aquella manera, los judios sefarditas toledanos conocieron una época de esplendor en los siglos XII y XIII. Su comunidad oscilaria entre 500 y 1.000 personas a finales del XII, y era, sin duda, la primera de España, además de influir sobre otras que se formaron en Castilla por entonces, incluyendo las andaluzas, después de la reconquista del XIII. La mayor parte de los 
judíos eran artesanos (sastres, carpinteros, herreros, carniceros, horneros) o pequeños agricultores propietarios de viñas, pero destacó una minoría de financieros, que actuaron a menudo como tesoreros o «almojarifes" de los monarcas, arrendadores de impuestos o grandes mercaderes. Entre ellos se cuentan las principales familias hebreas toledanas, desde el siglo XII al término de la Edad Media: Ibn Ezra, Ibn Shosan, Nehemías, Barchilón...

Los mozárabes, hispanocristianos que habían permanecido en la España islámica, recibieron un trato especialmente favorable después de la capitulación de Toledo. A su presencia y a su influjo se debe la persistencia de peculiaridades andalusíes en Toledo: hablaban y escribian en romance y en árabe, conocían bien el funcionamiento económico y político de una urbe hispanomusulmana (no hay que olvidar que el primer gobernador del Toledo reconquistado fue el conde mozárabe Sisnando Davidiz), cultivaban los campos y cubrieron el tránsito y la transmisión de técnicas entre ambas etapas, la islámica y la cristiana, debido a la fuerte emigración de musulmanes. Conservaron además, por algún tiempo, el empleo de la liturgia hispanovisigoda, cuyo uso como rito mozárabe sería restaurado por el arzobispo-cardenal Cisneros en 1508, en una capilla de la catedral toledana.

De todos modos, hay que precaverse frente al peligro de atribuirles una importancia mayor de la que tuvieron, basados en el hecho de que se conserve y haya publicado una abundante documentación mozárabe correspondiente, sobre todo, a la segunda mitad del siglo XII. Apenas la hay anterior, y ninguna de época hispanomusulmana. Sólo contaban la mozarabía de Toledo y, a mucha distancia, algunas otras (Talavera, Madrid, Maqueda, Guadalajara). En otros lugares o no hay mozárabes, o aparecen junto con los castellanos, como repobladores: así sucede en numerosas alquerias, y es muy raro que se les ceda alguna para ellos solos. Hay, en total, noticia de mozárabes en una cincuentena de alquerias. Posiblemente, la huida de mozárabes del valle del Guadalquivir incrementó su número en el siglo XII, y contribuyó a que mantuviesen por más tiempo sus peculiaridades culturales.

Esto se debia, también, a que disponian de derecho o fuero propio, reconocido por Alfonso VI, y a su promoción después de la conquista, puesto que, como hemos indicado, participan en los repartos de tierras y ocupan cargos urbanos (zalmedina, alguacil, alcalde), lo que permitió la formación de algunos linajes aristocráticos entre ellos, a lo largo del siglo XII, como los de Illán Pérez, Aben Lampader, Policheni, Cebrián, Imrán, Palomeque, etc.

La peculiaridad eclesiástica perduró por más tiempo, en algunos 
aspectos, y sobre ella se ha basado una consideración tal vez hiperbólica de lo mozárabe en Toledo. En efecto, después de la romanización inicial, en tiempos del arzobispo Bernardo de Sédirac y su clero "franco", hay de nuevo muchos sacerdotes mozárabes en la segunda mitad del XII y algunos conventos, como el de San Clemente, en los que predomina la mozarabía. La población mozárabe de Toledo quedó adscrita, después de la conquista, a seis parroquias, fuera cual fuese su punto de residencia en la ciudad, y esto creó un lazo de continuidad, porque tenían que pagar a ellas el diezmo todos los descendientes de mozárabes por línea masculina, según se dispuso en una reorganización del siglo XVI. Apenas habrá que decir que la población de la ciudad estaba ya muy mezclada entonces, y que fueron posibles errores y falsificaciones.

La fusión comenzó desde el momento de la conquista, mediante frecuentes matrimonios mixtos con castellanos, que se incrementan en la segunda mitad del siglo XII. En el XIII, la mayoría de las peculiaridades mozárabes habian desaparecido en el Toledo cristiano, o estaban en trance de hacerlo. Varios indicadores lo señalan así: en aquel siglo desaparecieron los apellidos musulmanes mantenidos por algunos mozárabes en época anterior, así como los nombres propios peculiares, tomados del martirologio. La documentación árabe de la mozarabía toledana, en comparación con las piezas en romance o latín de la misma procedencia, conservadas en el archivo de la catedral, muestra un predominio hasta 1125 , igualdad hasta 1150 , nuevo predominio en la segunda mitad del XII, descenso paulatino en la primera mitad del XIII y extinción en la segunda mitad y comienzos del XIV.

En otro orden de cosas se advierte, también, el proceso de asimilación y su auge durante la segunda mitad del siglo XII: me refiero al masivo movimiento de venta de propiedades rurales mozárabes, a menudo explotaciones pequeñas, individuales o familiares, durante la época de fuerte presión militar almohade, que se acompañó de hambres y carestías frecuentes $(1181,1183,1192$ y 1193, 1200, 1203 a 1207), según recuerdan los Anales Toledanos. Beneficiarios de aquellas ventas fueron personas e instituciones que ya eran grandes propietarios, en especial la sede arzobispal, el cabildo catedralicio y de Toledo, algunas iglesias y conventos, y cabe suponer que no sólo afectaron a los mozárabes, sino también a muchos otros pequeños propietarios. Lo cierto es que, en este caso, contribuirían a variar los fundamentos y funciones económicas del grupo y, con ello, a disolver su identidad. Las ventas comenzaron hacia 1156 , aumentaron a partir de 1168 , alcanzaron máxima intensidad entre 1188 y 1202 y, de nuevo, entre 1209 y 
1214, según indica el análisis de los 408 ejemplos registrados hasta 1230 .

El caso de los mozárabes toledanos muestra, en resumen, cómo la unidad de fe religiosa dista de garantizar la homogeneidad cultural. Aunque de ningún modo se les pueda considerar una minoría oprimida, lo cierto es que a lo largo de los ss. XII y XIII hubieron de fundirse en la cultura románico-europea de la nueva sociedad toledana. Desde mediados del XII, al menos, esta fusión fue impulsada por los poderes políticos $y$, sobre todo, eclesiásticos. Pero la presencia mozárabe fue fundamental durante 200 años para la transmisión y aceptación de rasgos culturales y organizativos procedentes del mundo hispanomusulmán, en el marco urbano de Toledo.

Al lado de estos elementos poblacionales antiguos, más o menos incrementados o disminuidos tras la conquista, cuentan los nuevos pobladores de origen castellano, peninsular y ultrapirenaico.

Los castellanos constituyen el grueso de la población, una vez pasados los primeros momentos, y su llegada continúa a lo largo de todo el siglo XII. Hay que incluir, con ellos, algunos gallegos y leoneses sujetos todos al mismo fuero, y casos sueltos de navarros, aragoneses y catalanes en la segunda mitad de dicho siglo. Señala Julio González, como indicadores claros del predominio poblacional castellano, la existencia de 23 parroquias en Toledo de rito latino frente a 6 de mozárabes, o el caso de las 33 aldeas del término o alfoz de la ciudad pobladas entre 1142 y 1170 , donde se cuentan 304 pobladores castellanos por 60 mozárabes y 15 francos. Pero, por ser la castellanización el fenómeno general y común, ha dejado relativamente menos huellas, o de menor brillo, que los hechos minoritarios antes de su asimilación.

Entre éstos, otro muy notable es la llegada a Toledo de repobladores francos, procedentes del $S$ de Francia, e incluso algunos de Italia e Inglaterra. El hecho no es infrecuente, pues también hay colonizadores francos en poblaciones del Camino de Santiago, y en otras de Castilla la Nueva, como Madrid, Talavera, Illescas o Cuenca, pero sí que es peculiar la fuerte identidad con que se organizaron en Toledo. Dispusieron de fuero propio y oficiales judiciales (merino, sayón), se asentaron en el barrio o zona comprendido entre la plaza de Zocodover, la catedral y el alcázar, con parroquia en la iglesia de Santa María Magdalena. Fueron, evidentemente, un factor de europeización y de dinamización de las actividades artesanales. Con todo, a partir de la segunda generación su integración con los castellanos fue en aumento, hasta llegar a la fusión total, de modo que, ya en el XIII, la palabra franco se refería a la condición de exento de ciertos impuestos directos, más que 
al origen étnico, y la toledana calle de francos, aun conservando su dedicación mercantil, no estaba poblada por gentes de aquel origen, o que conservaran memoria de que sus antepasados lo tuvieran. Todavia a fines del XII, sin embargo, tenian los francos cofradía propia. Sin duda, la fusión se vio favorecida porque apenas llegaron inmigrantes francos a Toledo en el XIII.

En los decenios que siguieron a la conquista hubo un grupo franco de especial importancia. Me refiero al clero que rodeó al primer arzobispo, Bernardo de Sedirac, y que tanto contribuyó a la romanización de la Iglesia hispana. En el monasterio de San Servando, por ejemplo, los primeros monjes fueron marselleses, pero lo abandonaron después del ataque almoravide de 1109. En las siguientes generaciones, las relaciones ultrapirenaicas de la Iglesia toledana conservaron importancia, debido a este aporte y contacto iniciales.

\section{IV.-ESTATUTOS JURIDICOS}

La formación de jerarquías sociales en la población cristiana se vio matizada, por lo tanto, debido a la pertenencia a diversas comunidades con estatutos jurídicos propios. Sólo paulatinamente predominaron los elementos comunes de organización, basados en la riqueza, la capacidad militar y la actividad económica y política, sobre estos factores peculiares.

Hacia 1101 la presencia de castellanos y francos era ya abundante, pasadas las dificultades repobladoras de los primeros momentos, y también habría concluido lo más nutrido de la emigración musulmana a otras tierras. En aquel momento otorgó Alfonso VI un fuero a los vicini mozárabes para asegurar el respeto y permanencia de sus propiedades. El vicinus mozárabe sólo podría venderlas a otro, pero no a populator castellano o franco. La identidad del grupo se garantizaba por el empleo del Liber ludicum, la antigua compilación legal hispanovisigoda, para sus litigios internos, y su libertad también, puesto que podian disponer de sus bienes y acceder al grupo de los caballeros quienes combatiesen de dicha forma y mantuvieran habitualmente caballo y armas. Parece que también en 1101 el rey definió el derecho particular de los grupos de populatores castellanos y francos. El derecho de los castellanos se conoce indirectamente a través del fuero dado a Escalona, en 1130, y el de los francos por una confirmación de 1136 que se refiere a su barrio y actividades económicas.

La unificación de regímenes jurídicos se consiguió a lo largo del 
siglo XII, aunque persistieran algunas disposiciones peculiares. Garcia Gallo ha demostrado ampliamente cómo el derecho de los castellanos fue "sumergido" por el Fuero Juzgo mozárabe, "e incrementado con distintas cartas, privilegios y refundiciones, llegó a constituir el Derecho de Toledo, que alcanzó amplia difusión” como modelo seguido para organizar las ciudades del Sur conquistadas en el siglo XIII.

Un primer paso en la unificación jurídica se produjo en 1118, cuando todos, mozárabes, castellanos y francos, llamados ya cives y no, separadamente, vicini o populatores, recibieron un fuero relativo a los privilegios y deberes de los caballeros y al régimen judicial y de propiedad que afectaba al conjunto de la población cristiana. El fuero de 1118 extendía el Liber ludicum para todos para el procedimiento procesal y para el homicidio, robo, rapto, aunque en los otros los castellanos podian acogerse al suyo privativo, liberalizaba la capacidad de compraventa, donación y herencia de tierras entre cristianos, aseguraba la libertad de los campesinos, aunque pagaran al rey el diezmo fiscal, de origen islámico, y la capacidad de todos ellos para acceder a la caballería. La situación de caballero comportaba el deber de partícipar en guerra ofensiva una vez al año, y el de defender permanentemente a la ciudad, de la que el caballero sólo podría ausentarse, dejando un sustituto, entre octubre y mayo, que era tiempo de tregua forzosa. Además, todos los vecinos de Toledo habían de contribuir a conservar las fortificaciones de la urbe, y se obligaban a no exportar caballos ni armas a tierra musulmana. En contrapartida, el rey regulaba la forma de repartir el botín obtenido en expediciones militares, aseguraba que la ciudad nunca dejaría de pertenecer a realengo, y ordenaba que nadie tuviera propiedades inmuebles en ella salvo sus vecinos y moradores habituales. Los toledanos recibieron otros privilegios, en el mismo texto de 1118, como eran quedar libres de prenda judicial, la inviolabilidad de sus domicilios frente a merinos y sayones, la exención de huéspedes forzosos, la libertad de matrimonio de las toledanas (dato importante, por las consecuencias sociales y económicas que tenía), la sujeción a jueces cristianos en los casos de litigio contra moros o judios, y ciertas exenciones fiscales para favorecer la liberación de cautivos, situación frecuente en aquella tierra de frontera. El año 1118 es, en conclusión, la fecha inicial del largo proceso acumulativo de privilegios y libertades que constituirían el «derecho de Toledo", común a todos sus vecinos cristianos y aplicado no sólo en la ciudad, sino en todas las pueblas del territorio, fuera cual fuese su jurisdicción. Un nuevo privilegio general en 1155 y otros privilegios y cesiones en la segunda mitad del s. XII, citados por Julio González, completan esta enumeración. 
Aunque los textos jurídicos son, aparte de su valor histórico intrínseco, un punto de vista excelente para comprender realidades sociales, éstas se aclararán un poco más si consideramos también las funciones económicas de Toledo en aquellos siglos, y los procedimientos de su organización gubernativa y administrativa.

\section{V.-TOLEDO, CENTRO ECONOMICO}

Toledo fue tal vez el principal centro de intercambios económicos de Castilla en los siglos XII y XIII. Contribuyeron a ello, también, la variedad de sus producciones agrarias y artesanas y el mayor volumen y fluidez de moneda en circulación, debido a la proximidad e influencia del sistema hispanomusulmán.

Los documentos mozárabes nos hablan sobre la intensa actividad económica de la aristocracia urbana, que obtiene su renta del alquiler de casas, tiendas, talleres urbanos, de propiedades rurales, a veces, incluso, del préstamo de dinero, aunque ésta era tarea más frecuente entre los judíos, o de la participación en empresas mercantiles. Es una situación poco típica entre las aristocracias urbanas de la época, aunque también en Toledo acabarían imponiéndose los ideales caballerescos, propios de la sociedad feudal, más adelante.

La situación fronteriza permitió la continuidad del comercio con la España islámica. Así lo demuestra la mención a recuas en el camino entre Toledo y Córdoba, los datos sobre tejidos, joyas y otros productos procedentes de Sevilla, Murcia o Valencia en Toledo, y la misma prohibición, expresada en 1118, de exportar caballos y cueros a Al-Andalus. Veinte años después Alfonso VII eximía a los toledanos de portazgo en todo el reino con tal de que no comerciasen con la España islámica, pero es evidente que siguieron haciéndolo. El ganado, los cueros, la miel y cera y, sin duda, algunos productos prohibidos constituirian su oferta habitual.

Por este motivo, Toledo fue una puerta principal de entrada para el régimen monetario islámico en Castilla. Allí había acuñado Alfonso VI moneda de vellón, a poco de conquistar la ciudad. Allí continuarían circulando el oro y la plata islámicos y, desde el segundo tercio del siglo XII, los maravedíes o morabetinos de oro almoravides $(3.90 \mathrm{~g}$ de peso), que comenzó a acuñar con su efigie y leyenda Alfonso VIII, en la propia Toledo, a partir del último cuarto de aquel siglo (años 1172 a 1223).

A la fluidez del comercio y al uso de moneda contribuyó también la 
guerra, sin duda alguna, porque, además de ser causa de destrucciones y cautiverios, proporcionaba botín - que llega a ser una forma habitual de ganancia o empresa económica, y obligaba a mantener un comercio continuo para abasto de guarniciones y huestes.

Además, Toledo conservó su organización económica urbana de la época anterior $y$, en este aspecto, fue un modelo del que aprendieron muchas otras ciudades castellanas de los siglos XII y XIII, y sirvió para familiarizar a los cristianos con el sistema urbano que encontraron en Andalucía y Murcia durante sus conquistas del siglo XIII. Hay que aludir, ante todo, a la organización de los oficios artesanos y mercantiles, bajo la vigilancia de alamines - llamados en otras partes veedores o alcaldes-designados por la autoridad municipal para controlar calidades y precios, y para dirimir litigios internos. Es la raíz islámica del gremialismo castellano, una entre las varias que éste tuvo.

Sin embargo, los artesanos y comerciantes fueron tanto mozárabes, francos y castellanos como musulmanes y judíos. En la artesanía toledana destacaron los ramos del metal, cuero, pieles y armas, que dieron lugar a manufacturas de gran calidad, pero la ciudad no fue, en cambio, un centro textil de importancia. Hubo también gran población artesana dedicada a los oficios de construcción y alimentación, como correspondía a una ciudad importante. Gracias a todos ellos se conservaron y transmitieron muchas técnicas de la época hispanomusulmana.

$Y$, también, los mismos lugares de trabajo y venta, cosa que importa para considerar la permanencia de los usos urbanísticos anteriores. En efecto, Toledo conservó sus almacenes o mesones y alhóndigas, especializados en diversos productos, su alcaicería y tiendas del rey, dedicadas al comercio fijo y permanente, sus mercados o sūq en diversas plazas, a veces especializados, como ocurría con Zocodover, que era el mercado de ganados, con el sũq de los cambistas o con el de los drogueros y herbolarios.

A la población de artesanos y comerciantes hay que añadir la de los corredores de comercio, arrieros y carreteros, que contribuian a su actividad mercantil y a la relación continua con la economía agraria del término. Nos hallamos, en conclusión, ante un modelo de economía urbana mucho más rico y diversificado que el de otras ciudades castellanas de la época, donde el predominio de las actividades y rentas agrarias era más evidente. No obstante, también en Toledo la tierra era principal base de riqueza, aunque el comercio la completara, y todos los caballeros o aristocracia urbana eran, ante todo, propietarios, aunque no explotadores directos, ya que estaban generalizados los regí- 
menes de cesión de usufructo en aparcería o en arrendamiento por períodos cortos de tiempo.

\section{VI.-EL GOBIERNO DE LA CIUDAD Y SUS PECULIARIDADES}

El gobierno de Toledo tuvo rasgos fundamentales en común con el de otras ciudades castellanas, en especial porque la militarización de la sociedad producía el habitual predominio de los caballeros sobre el resto de la población, que combatía a pie, y este rasgo reforzaba a otros, propios de las sociedades feudales, para que los cargos de gobierno se designasen ex nobilissimis, según se lee en algún documento, a pesar de las peculiaridades poblacionales y mercantiles de Toledo. Pero éstas se dejaban sentir también: En Toledo no hubo concejo o concilium de vecinos, al modo de otras ciudades castellanas, ni necesidad de montar una administración local, ya que se heredaron los mecanismos de la época islámica, ni tampoco lucha contra una situación señorial anterior en la que madurase la institución municipal, sino concesión de fueros y pactos o privilegios por la Corona a los diversos grupos de habitantes, o a todos ellos juntamente. En consecuencia, no se abrió paso una autonomía municipal, sino que la ciudad siguió gobernada por el rey y los agentes y magistrados que él designaba entre los notables toledanos.

A finales del siglo XIV escribía el canciller Pedro López de Ayala que Toledo no era un concejo al modo común castellano, ni tenía la ciudad sello ni enseña propios, ni asamblea cerrada o regimiento que hubiera sucedido a la asamblea abierta de todos los vecinos. Sin embargo, para entonces, los oficiales y caballeros que regian la ciudad formaban de hecho una asamblea similar al regimiento de otras ciudades $y$, desde 1423, al adoptarse en Toledo la reglamentación municipal sevillana, desaparecieron las últimas diferencias.

Estas fueron más notorias, por tanto, en los siglos XII y XIII, en relación con los municipios ampliamente autónomos de las extremaduras, aunque, repito, las bases sociales del poder y su distribución eran muy semejantes. En Toledo era el rey quien designaba a los oficiales o aportellados encargados de la gestión municipal, que duraban en sus cargos por tiempo indefinido. La máxima jerarquía eran los dos alcaldes, uno para castellanos y otro para mozárabes, asistidos en sus funciones judiciales por diez notables y por diversos escribanos de latín y árabe. Eran sucesores de los antiguos cadies - su mismo nombre lo indica- $y$, como ellos, tenían lugartenientes o hákim. En el siglo XIII actúan por encima de ellos, como jueces de apelación, unos alcaldes 
del rey. La policía y ejecución de las decisiones judiciales corría a cargo de los alguaciles - son los antiguos wazir o visir-, tanto en la ciudad como en el término sujeto a ella. La administración general de la ciudad estaba en manos de un zalmedina (sahib al-madina), cargo que, como el de zabazorta (sahib al-shurta), o jefe de la vigilancia urbana, había desaparecido antes de finalizar el siglo XII. Los de alcalde y alguacil, no, e incluso los nombres se adoptan en otras ciudades castellanas, donde había magistrados con semejantes funciones. Completaban el cuadro de oficiales locales el almotacén (muhtashib), que organiza el mercado urbano y los oficios artesanos, los almojarifes o tesoreros y recaudadores de impuestos y el pregonero.

Otra peculiaridad toledana era la separación entre administración civil y oficios militares, cosa ignorada en las demás ciudades del reino. Al frente de la organización militar situaba el rey a un alcaide (qaid), llamado también dominus villae o princeps militiae, del que dependian los otros alcaides de las fortificaciones y castillos toledanos.

Un aspecto en el que variaron bastantes cosas con relación a la época musulmana fue el relativo al territorio o alfoz sobre el que se extendía la jurisdicción toledana. Sin duda, disminuyó mucho, puesto que diversas villas, como Madrid, Guadalajara, Maqueda, Hita o Talavera, integraron en sus alfoces partes del que antaño fuera de Toledo. Además, la ciudad no delimitó por completo el suyo hasta entrado el siglo XIII, sobre todo en la zona S, donde era amplísimo, porque lindaba con el de Córdoba en algunos puntos.

Por todos estos motivos singulares, y por la complejidad de su derecho local, Toledo no fue un modelo seguido para la organización municipal de otras ciudades castellanas y leonesas en los siglos XII y XIII. Los burgos del Camino de Santiago y las ciudades-fronteras de las extremaduras obedecen a otros modelos, por ejemplo. Por el contrario, el influjo de Toledo fue considerable cuando hubo que organizar las grandes ciudades hispanomusulmanas conquistadas y repobladas en el siglo XIII, como Sevilla, Córdoba o Murcia y, a su vez, la experiencia y normas surgidas en estas ciudades, en especial Sevilla, se aplicaría a Toledo en la baja Edad Media, como hemos indicado.

La conquista de Toledo significó, también, la reincorporación a territorio cristiano de la antigua sede episcopal primada de Hispania, a la que se renovó con todo su esplendor, tanto por motivos eclesiásticos como políticos. El arzobispo de Toledo, canciller mayor del rey desde la 
segunda mitad del siglo XII, era el cargo eclesiástico más importante del reino, y su sede la más rica en renta, de modo que, ya en el siglo $X V I$, escribiría un autor que "no prelado sino papa parece». Los orígenes de aquella riqueza hay que buscarlos en la generosa dotación de la sede, hecha en 1086 por Alfonso VI, con bienes inmuebles urbanos, rústicos y alquerías, en el cobro de diezmo eclesiástico y en su propia capacidad de reinvertir renta en compra de fincas, según hemos visto, por ejemplo, con relación a las propiedades de mozárabes, en la segunda mitad del siglo XII y comienzos del XIII. Bajo el mecenazgo eclesiástico se realizarían buena parte de las obras culturales y artísticas del Toledo medieval.

Conviene destacar, para que nuestra visión del gobierno y administración toledanos sean mejores, que, en el terreno eclesiástico, la ciudad ejerció una capitalidad mucho más importante que en el civil. El territorio de la archidiócesis era el más extenso de toda la península ibérica, al comenzar el siglo XIII, puesto que ocupaba toda Castilla la Nueva, con excepción de las diócesis de Cuenca y Sigüenza, y parte de la actual Extremadura, aunque en la cuenca del Guadiana, especialmente, estuviera sujeto a la jurisdicción especial de las Ordenes Militares. Constaba de siete arcedianatos, subdivididos a su vez en 23 arciprestazgos. Pero es que, además, Toledo era cabeza de una amplia provincia eclesiástica en la que se integraron diversas diócesis sufragáneas: Palencia, en 1099, Osma, Sigüenza y Segovia, a comienzos del siglo XII; Cuenca, desde 1177; Jaén y Córdoba, después de su conquista en el XIII.

He aquí, pues, la imagen de una gran ciudad, la mayor de Castilla, en su primera época después de la conquista cristiana, cuando era centro de una amplísima región fronteriza, desde finales del siglo XI a comienzos del XIII. Toledo fue un caso peculiar, distinto al de otros tipos de ciudad castellana, según hemos indicado, porque en ella se produjo, por primera vez, la fusión del pasado hispanomusulmán con las aportaciones, necesidades y criterios de los repobladores castellanos y porque, además, fue una fusión más matizada y lenta, debido al respeto a los mudéjares que permanecieron y, sobre todo, a la presencia de los mozárabes. En esto hay una gran diferencia con las ciudades andaluzas conquistadas en el XIII, donde no había mozárabes y donde la sustitución de la población musulmana por la cristiana fue mucho más rápida y radical. La importancia de la judería contribuyó también a enriquecer las posibilidades de intercambio y coexistencia cultural en 
Toledo, así como la realidad misma de una frontera abierta y cambiante durante siglo y medio, a pesar de las hostilidades que en ella se desarrollaron. La presencia de francos, especialmente clérigos, estableció, por su parte, una relación continua y fecunda con Europa que singularizó igualmente a Toledo dentro de la Castilla de su tiempo.

Una vez que hemos considerado los aspectos poblacionales, las realidades de la economía urbana y agraria, las instituciones y el derecho toledanos, en lo que muestran de sintesis entre varias épocas y grupos, aunque siempre bajo la hegemonía del sistema social y de civilización europeo-románico, traído por los conquistadores y pobladores castellanos, estamos en condiciones de comprender mejor lo que el Toledo cristiano, mudéjar y judío significó como centro cultural, urbanístico y artístico en la plenitud del medievo hispánico.

\section{VII.-TOLEDO Y LA TRANSMISION DE CULTURA INTELECTUAL}

La situación de frontera entre dos civilizaciones permitió a Toledo jugar un papel decisivo como lugar de transmisión de cultura, a través de las traducciones del árabe al romance, y de éste al latín, de numerosas obras de filósofos y científicos musulmanes y griegos, que hasta el siglo XII no había conocido Europa. En aquella tarea destacaron, primero, algunas ciudades del valle del Ebro, como Tarazona y Zaragoza, pero desde 1160 , aproximadamente, Toledo alcanzó la primacía absoluta. La importancia de los centros de traducción hispanos, en especial el de Toledo, fue posiblemente superior a la del centro siciliano, por la continuidad y cantidad de las traducciones. En todo caso, en torno al Toledo de los siglos XII y XIII, se produjo el primer gran impulso intelectual que experimentó la España medieval.

No es cierto, sin embargo, que haya existido una "Escuela de Traductores de Toledo", bajo el mecenazgo inicial del arzobispo toledano Raimundo (1126-1152). Hubo diversos traductores, a lo largo de casi dos siglos, y varios mecenazgos, arzobispales o reales, pero no una Escuela dotada de continuidad y sentido de conjunto. Trabajaron como traductores judios y mozárabes - conocedores del árabe--, clérigos castellanos y, sobre todo, ultrapirenaicos, que vertían las obras al latín y trasladaban el resultado del trabajo a sus respectivos paises. Veamos algunos nombres y momentos principales:

Entre 1120 y 1160 trabajó intensamente el mozárabe Juan de Sevilla, traductor de numerosas obras de astronomía, meteorología y matemática, entre ellas las famosas Tablas astronómicas que el toledano Azar- 
quiel había puesto a punto en el siglo XI. Fue también muy importante la colaboración entre el arcediano de la catedral toledana, Domingo Gundisalvo, y el mozárabe Juan David, ambos bajo el mecenazgo del arzobispo Raimundo: tradujeron diversas obras de metafísica de Avicena, Al-Gassalí, Al-Farabí e Ibn Gabirol, que contribuyeron a la formación de la filosofía europea. Recordemos también la figura del judío Pecuro de Toledo que, entre otras cosas, tradujo al latin el Corán por encargo del abad de Cluny, Pedro el Venerable, durante el viaje que éste hizo por tierras hispanas en 1142.

Desde 1160 se convirtió Toledo en centro principal de las traducciones realizadas en suelo ibérico. Sin abandonar los temas y autores anteriores, el interés se centró en la obra filosófica y científica de Aristóteles. En su busca acudieron a Toledo diversos sabios extranjeros. Por ejemplo, Gerardo de Cremona, entre 1167 y 1187, que se valió de los servicios del mozárabe Galib, pero aprendió árabe él mismo para traducir a Tolomeo, Galeno, Avicena y, sobre todo, a Aristóteles. O Miguel Scoto, hacia 1217, que continuó su obra de traductor de Aristóteles en Palermo, bajo la protección de Federico II, e hizo lo propio con los comentarios aristotélicos de Averroes, hacia 1230, poco antes de que los tradujese también en Toledo Hermann el Alemán, en torno a 1240: las bases del averroísmo latino y de la influencia de Averroes sobre el mismo Santo Tomás estaban puestas.

En la segunda mitad del siglo XIII la actividad traductora se renueva en Toledo, bajo el patrocinio del rey Alfonso $X$ el Sabio, que utilizó rabinos judios y alfaquíes musulmanes, junto con clérigos cristianos, para traducir del árabe al castellano, con mayor frecuencia que al latín. Apenas citaré algunos nombres significativos: Abraham alfaquí, Bernardo el arábigo, Juda ben Mosé, Salomón, o los clérigos Garci Pérez, Juan de Aspa y Álvaro de Oviedo. Algunos de aquellos traductores actuaron también en Sevilla, Murcia e incluso tendrían relación con la presencia de traductores judíos en Montpellier, a comienzos del XIV. Con su colaboración, la obra cultural de Alíonso $X$ alcanzó dimensiones nuevas: se tradujo el Calila e Dimna, los Bocados de Oro y el Poridad de Poridades, colecciones de cuentos orientales, diversos tratados de astronomía que sirvieron de base a los Libros del Saber de Astronomia, del Rey Sabio; algunos textos agronómicos hispano-musulmanes del siglo XI, y, una vez más, a Avicena y Averroes. Cuando termina la actividad de los últimos traductores, hacia 1285, muere un episodio singular e importante de la historia cultural europea que tuvo en Toledo las condiciones más propicias para su realización. 


\section{VIII.-LA HUELLA DE LAS CULTURAS MEDIEVALES EN EL URBANISMO TOLEDANO}

Podria pensarse que el singular pasado histórico de Toledo durante los siglos XII al XIV habría dejado como herencia un gran patrimonio urbanístico y arquitectónico que nos sirviera hoy para revivirlo. Toledo es, sin duda alguna, una ciudad bellísima e impresionante, cuya historia se manifiesta en sus calles y monumentos. Pero muchos de ellos son de épocas posteriores a las que aquí estudiamos. De la ciudad se ha dicho que, con excepción de la catedral, fue hasta el siglo XV «de tierra, argamasa, mampostería y ladrillo" - materiales todos ellos muy propios de la arquitectura mudéjar-. Pero el mismo autor de la frase, que es el gran arquitecto e historiador del mudejarismo Leopoldo Torres Balbás, nos ha enseñado a caminar por el "Toledo oculto" medieval y mudéjar, a través del "Toledo aparente». Recorreremos ahora algunos tramos del itinerario.

El urbanismo del Toledo medieval cristiano debía mucho a las épocas pasadas, en especial la romana y visigoda, pero, sobre todo, conservaba los rasgos de la ciudad hispanomusulmana. El emplazamiento era antiguo, como en tantas otras ocasiones, y aprovechaba unas condiciones magníficas de defensa y refugio, sobre unos escarpes de roca, con el río Tajo como gran foso natural que circundaba a la ciudad en más de sus dos terceras partes. Toledo, extendida sobre $106 \mathrm{Ha}$. de superficie amurallada, era la «ciudad más fuerte de la península»

Sus murallas, de origen romano y visigodo, habian sido profundamente restauradas a comienzos del siglo IX $y$, de nuevo, en 1100 por Alfonso VI, y después del terremoto de 1221. En ambas ocasiones se utilizaron materiales anteriores, y el rey cristiano conservó los procedimientos defensivos musulmanes, tanto en el clásico sistema de puertas como mediante la construcción de corachas, es decir, lienzos de muraIla que aislaban el espacio comprendido entre el muro principal y el río para proteger así azudas y manantiales, molinos y tenerías, pasos de barca.

Las murallas que defienden la ciudad por el lado $\mathrm{N}$, no circundado por el río, eran dobles. Además de la muralla de la medina o ciudad, propiamente dicha, donde se abre hoy la Puerta del Sol, estaba murado el arrabal, el único importante de Toledo, construido a partir del año 814 , y en sus paneles se abrían otras puertas famosas, la de Almaguera o Bisagra vieja, y la de Bisagra nueva, reconstruida en el siglo XVI.

En el sistema defensivo se incluía el único puente de piedra con que contó Toledo desde época romana hasta el siglo XIII. Al ser el puente, 


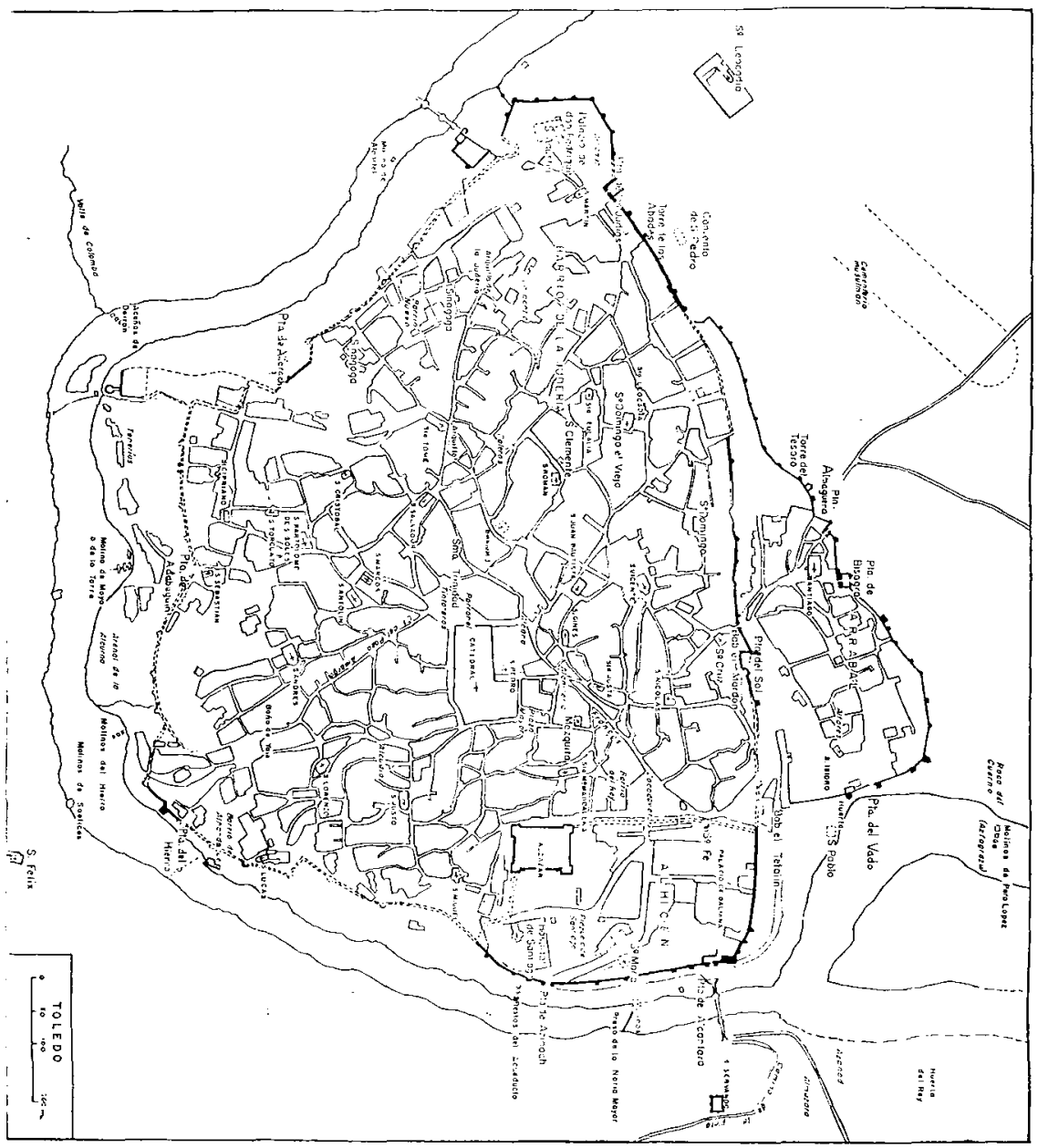

Toledo medieval (J. González) 
por excelencia, no necesitó nombre, aunque hoy le conozcamos con el término árabe, duplicado por el castellano: puente de alcántara (alqantara $=$ el puente). Fue totalmente reconstruido en 997, y estaba defendido por una torre en su cabecera, así como, al otro extremo, por el monasterio-castillo de San Servando, que ordenó edificar Alfonso VI en los años que siguieron a la conquista, y que es el mejor ejemplo de arquitectura militar del Toledo cristiano-mudéjar, a pesar de sus numerosas restauraciones. El puente también fue rehecho, ya en época cristiana, en 1259 y Alfonso $X$ ordenó la construcción de otro, el de San Martín, en el extremo opuesto de la ciudad.

Como tantas ciudades islámicas, Toledo disponía de una ciudadela o reducto especial donde se alojaban el gobierno urbano, la guarnición $y$, en caso de rebelión ciudadana, algunos habitantes. La ciudadela podía ser, también, último punto de defensa frente a un atacante exterior. Parece que se construyó a finales del siglo VIII, como consecuencia de las revueltas urbanas de muladíes y mozárabes, y recibió el nombre de alhicén, por situarse en una zona más elevada. Al ser propiedad gubernamental, Alfonso $\mathrm{VI}$ entró inmediatamente en posesión de todo el Alhicén o ciudadela, desde 1085. Allí había dos alcázares, de los que uno, el Palacio de Galiana, ha desaparecido, y el otro se conserva en su nueva planta hecha en el siglo XVI. Alli, también, se establecieron la cárcel pública y la ceca o casa de moneda. Como en SeviIla, Córdoba o Granada, Toledo heredó, por tanto, un barrio del alcázar procedente de su pasado islámico.

Los contornos urbanos de Toledo también expresaron aquella herencia durante varios siglos. Se conservó, por una parte, el recuerdo del maqavir o cementerio musulmán extramuros, aunque es bien sabido que los cristianos medievales no seguían aquella práctica de enterramiento. Al lado opuesto de la ciudad, junto al castillo de San Servando, seguiría en uso la gran explanada o musara destinada a ejercicios y juegos ecuestres, y a paradas o alardes militares. Pero, sobre todo, Toledo conservó hasta el siglo XVII buena parte de su contorno de huertas y jardines, con pequeñas granjas o almunias, procedentes de la época musulmana, como en otras ciudades españolas. Los sistemas de elevación y uso del agua del Tajo estuvieron muy desarrollados para atender al mantenimiento de aquel paisaje rural sub-urbano. La principal zona de huertas estaba en la vega alta del Tajo, donde se alzaba la Huerta del Rey, llamada también palacio de la buhayra (buhayra es alberca), propiedad de los reyes taifas y, después, de los cristianos. Cerca estaba la almunia de la infanta Doña Sancha, a mediados del siglo XIl. Entre el río y el lienzo de la muralla había también diversos 
espacios de huerta, que se ampliaban al otro extremo de la ciudad, en la llamada Vega Baja, en torno al convento y arrabal de Santa Leocadia, que, por lo que sabemos, es creación de época cristiana, aunque sobre asentamientos de época visigoda.

Pasemos ahora al interior de la ciudad. En él, lo característico era la fragmentación del espacio urbano, la vida propia de cada uno de sus elementos, a partir del más pequeño de ellos, que es la casa o el grupo de casas que forma una manzana. La irregularidad de la red viaria es el resultado de una forma peculiar de concebir la vida urbana en países de Islam, aunque, en el caso de Toledo, se añade otra razón, como es la complicación y dificultad topográficas. De todos modos, se distingue, como en todas las ciudades de herencia islámica, algunas calles principales, o ejes de tráfico que desembocan en puertas de la muralla. En Toledo son las de Santo Tomé, Pozo Amargo y la de Francos. Junto a ellas, las callejas secundarias que separan manzanas amplias e irregulares, y en tercer lugar, penetrando en las manzanas para uso de sus vecinos, multitud de callejones ciegos, llamados adarves, que a menudo tenían puertas para su cierre nocturno. Hoy han desaparecido bastantes, pero en los planos del siglo XIX se observan más de cincuenta, sobre todo en el triángulo formado entre la catedral, la iglesia de San Vicente y el alcázar, que era tal vez la zona más antigua de la ciudad $y$, desde luego, la más densamente poblada. Conserva Toledo también algunos aspectos de su antiguo paisaje urbano, en forma de saledizos, arquillos transversales, "alqorfas", ajimeces o ventanas de reja de madera, y en la misma tortuosidad y estrechez de sus calles, aunque todo ello matizado por el urbanismo moderno que, entre otras cosas, generalizó el pavimentado.

En la ciudad se distinguen diversos barrios, y también la medina, propiamente dicha, y los arrabales. La tendencia general en ciudades islámicas medievales era la agrupación en barrios residenciales según el origen étnico o la condición religiosa de sus pobladores, pero en Toledo esto no había sido así: los mozárabes vivieron siempre en toda la ciudad, y así continuó sucediendo después de la incorporación a Castilla. Los repobladores castellanos hicieron to mismo. Parece, en cambio, que los primeros grupos de francos se instalarían en el barrio en torno a la calle que lleva su nombre. De todos modos, el barrio mejor caracterizado era la judería, ya desde época musulmana, aunque es posible encontrar moradores judíos en otras partes de Toledo. Puede observarse en el plano adjunto cuál era el emplazamiento de esta judería, la mayor de Castilla y, seguramente, también la mejor estudiada. En lo que concierne a los arrabales, la gran extensión de 
Toledo hizo innecesaria su multiplicación. Como ocurrió en Sevilla, hubo sólo uno durante toda la época medieval, cuyo origen, como ya he dicho, se remonta al siglo IX.

Hay que descubrir también las huellas del Toledo "oculto" mediante la localización de diversos centros y funciones urbanas, y a través de la historia de sus edificios, o de los emplazamientos que han mantenido durante siglos. La mezquita mayor, alzada sobre el emplazamiento de la iglesia episcopal hispanovisigoda, era el principal centro, puesto que, en la ciudad islámica, ejerce funciones de centralidad urbana comparables a las del foro romano o a las de la plaza mayor hispanocristiana. En Toledo, la mezquita mayor fue convertida en iglesia-catedral en 1086, y su edificio continuó utilizándose hasta que, como consecuencia del terremoto de 1221, su deterioro llevó a sustituirlo por la actual catedral gótica.

En el entorno de la mezquita mayor, luego catedral, se conservó buena parte de la actividad mercantil de la ciudad, y muchos de los lugares de encuentro y sociabilidad. Allí estaban, por ejemplo, los principales grupos de tiendas fijas, de cuyo nombre (al-janat) deriva el actual topónimo toledano A/caná. Eran edificios muy pequeños, con puerta de doble hoja horizontal abierta a la calle, que reunían a veces la condición de punto de venta con la de taller artesano. En ocasiones disponían de una planta superior para almacén o dormitorio, pero no eran casas de vivienda. Su alquiler por el rey, o por la iglesia catedral, era una buena fuente de renta. Al lado de la catedral continuó, también, la alcaiceria o mercado público, de propiedad regia, formado por tiendas fijas y cerrado por las noches. $E$, igualmente, diversos mercadillos o zocos y azoguejos (sũq), repartidos por especialidades y oficios. Por ejemplo, los zocos de drogas, especias y perfumes (los Alatares o Herbolarios) están muy próximos a la catedral, tanto en Toledo como en Sevilla, los de "alfayates" o sastres o ropavejeros, el de los cambiadores de moneda..., la misma proximidad del núcleo mercantil de la calle de Francos demuestra esta permanencia topográfica, en el paso de la época musulmana a la cristiana.

En el restante espacio urbano se hallan también ejemplos de continuidad, en la presencia de mercados especializados: carniceros, bruñidores, alfareros del barrio de San Ginés, mercado de las caballerías o Zocodover. También, en el uso continuado de almacenes o alhóndigas, según el modelo arquitectónico islámico, que daría lugar a los «corrales de vecinos" en los siglos cristianos. $Y$, por último, en el empleo de baños públicos (hamman), de los que hay noticias sobre una docena, al menos, en el siglo XII. 
Otro tipo de continuidad y cambio, al mismo tiempo, es el que afectó a los edificios de uso religioso. Algunas mezquitas y oratorios musulmanes continuaron en uso, pero la mayoría se desafectó de su función religiosa, o bien pasaron a ser iglesias cristianas. Por ejemplo, la de Santa Cruz o ermita del Cristo de la Luz, cuya parte musulmana se concluyó en el año 999. En general, el culto cristiano tuvo suficiente con antiguas mezquitas o con viejas iglesias mozárabes, hasta fines del siglo XII, entre ellas las de El Salvador, San Andrés, San Sebastián, Santas Justa y Rufina, San Ginés, Santa Eulalia y San Torcuato. A pesar de las profundas reformas posteriores, muchas de ellas de los siglos XVI y XVII, es posible encontrar todavía fragmentos de época califal, taifa y aun visigótica en algunos de estos templos.

\section{IX.—CONCLUSIÓN SOBRE EL TOLEDO MUDÉJAR}

"Conviene destacar el hecho de que, a pesar de ser Toledo una de las ciudades más importantes de la España cristiana en el siglo XII, en la que residian con frecuencia el monarca y parte de la nobleza, capitalidad eclesiástica de la península, regida en algunas épocas por prelados extranjeros, el arte románico no penetró en ella ni en su comarca. Los maestros y obreros mudéjares locales satisfacían plenamente, sin duda, las necesidades arquitectónicas de la época" (Torres Balbás).

$Y$ aquel "estilo mudéjar», realizado por maestros musulmanes y también por cristianos que lo habian aprendido, utilizaba el ladrillo y la mampostería. La catedral gótica sería "el único templo..., hasta fines del siglo XV, de piedra y arte exótico". Por la fragilidad de los materiales, unido a terremotos, aguaceros y otras circunstancias, se explica la pérdida casi total de los monumentos anteriores a la conquista, y el deterioro de los templos toledanos en estilo mudéjar que comenzaron a alzarse desde comienzos del XIII, a menudo como sucesores o para completar y reformar a los edificios que desaparecían.

De todas maneras, los restos arquitectónicos abundan. En Toledo llegó a haber el número, altísimo para entonces, de 29 parroquias, algunas de las cuales habian ya desaparecido o se habian transformado en conventos antes de concluir la Edad Media. Se ha de añadir la presencia de sinagogas, aunque no hay documentos sobre ellas hasta bien entrado el siglo XIII, y de algunas construcciones civiles.

En general, el esplendor del arte mudéjar, del que Toledo fue centro muy principal, se extiende desde finales del siglo XIII hasta finales del $X V$. Fue una de las grandes creaciones hispánicas bajomedievales, pre- 
cisamente en la época en que la presencia numérica y el peso social de los musulmanes mudéjares en Castilla era ya mucho menos importante que en los siglos XII y XIII. Curiosa manifestación tardía de cómo una cultura, una sociedad aceptan y asumen - -0 , tal vez, incluso vuelven a crear- una parte notable del legado artístico, de las técnicas arquitectónicas y decorativas, de las formas de vida urbana, de otra sociedad anterior, a la que se había desplazado en todos los demás terrenos. Pero nada puede suplir, en este aspecto, a la visión directa: Toledo, aunque conserva monumentos excelentes, no los tiene tal vez de calidad y categoría tan notorias como los conservados en otros puntos de Castilla, en Andalucía o en Aragón. Los rodea, sin embargo, de un marco urbano incomparable, que da todo su significado histórico y social a la obra de arte $o$ al resto arqueológico.

\section{BIBLIOGRAFIA}

RAMON MENENDEZ PIDAL, La España del Cid, Madrid, 1947, 2 vol.

ANGEL GONZALEZ PALENCIA, Los mozárabes de Toledo en los siglos XII y XIII, Madrid, 1926-1930, 4 vol.

- Moros y cristianos en la España medieval, Madrid, 1945.

JULIO GONZALEZ, Repoblación de Castilla la Nueva, Madrid, 1975-1976, 2 vol.

JEAN GAUTIER-DALCHE, Historia urbana de León y Castilla en la Edad Media (siglos IXXIII), Madrid, 1979.

REYNA PASTOR, cPoblamiento, frontera y estructura agraria en Castilla la Nueva», en Cuadernos de Historia de España, XLVII-XLVIII (1968), 171-255.

- «Problèmes d'assimilation d'une minorité: les mozarabes de Tolede (de 1085 a la fin du XIII" siècle)", en Annales E.S.C. (París), 1970, 351-390.

- Del Islam al Cristianismo... Toledo, siglos XI-XIII, Barcelona, 1975.

MARCELIN DEFOURNEAUX, Les français en Espagne aux $X I^{\circ}$ et $X I^{\circ}$ siècles, París, 1949.

PILAR LEON TELLO, Judios de Toledo, Madrid, 1979.

ALFONSO GARCIA GALLO, "Los fueros de Toledo", en Anuario de Historia del Derecho Español, XLV (1975), $341-488$.

JUAN FRANCISCO RIVERA RECIO, El arzobispo de Toledo don Bernardo de Cluny (10861124), Roma, 1962.

- La Iglesia de Toledo en el siglo XII (1086-1208), Roma, 1966.

- Los arzobispos de Toledo en la Baja Edad Media (siglos XII-XV), Toledo, 1969.

ANGEL GONZALEZ PALENCIA, El arzobispo don Raimundo de Toledo, Madrid, 1942.

CLAUDIO SANCHEZ-ALBORNOZ, “El Islam de España y el Occidente», en L'Occidente e I'/slam nell'Alto Medioevo. XII Settimana di Studio, Spoleto, 1964-1965, pp. 149-308.

LEOPOLDO TORRES BALBAS, Ciudades hispanomusulmanas, Madrid, 1971, 2 vol.

- "Por el Toledo mudéjar: el Toledo aparente y el oculto", Al Andalus, XXIII (1958), 424444.

- Arte almohade. Arte nazari. Arte mudéjar, en Ars Hispaniae, Historia Universal del Arte Hispánico, vol. IV, Madrid, 1949. 
A. MARTIN GAMERO, Historia de la ciudad de Toledo. Sus claros varones y monumentos, Toledo, 1862 (repr. 1979, 2 vol.).

JULIO PORRES, Historia de las calles de Toledo. Toledo, 1971, 2 vol.

JOSE AMADOR DE LOS RIOS, Toledo pintoresca o descripción de sus célebres monumentos, Madrid, 1845 (repr. 1976). 